\title{
Cardioprotection: definition, classification, and fundamental principles
}

\author{
Wolfgang Kübler, Markus Haass
}

\begin{abstract}
Definition
In English, as in German, the word protection has two meanings: it implies not only "preservation" but also "favouritism" or "patronage"-as shown by the word "protegée". Both definitions may be appropriate when terms, such as "cardioprotection", "nephroprotection", or "vasoprotection" are used by marketing strategists to describe supposed beneficial pharmaceutical effects that cannot be adequately documented in clinical conditions.

The term "cardioprotection" is nowadays mainly used to describe the beneficial effects of angiotensin converting enzyme (ACE) inhibitors in patients with impaired left ventricular function. When such a definition is restricted to a single group of drugs (ACE inhibitors) and to a single disease (congestive heart failure) its use is neither precise nor practical.

Cardioprotection includes "all mechanisms and means that contribute to the preservation of the heart by reducing or even preventing myocardial damage". If this definition is accepted then cardioprotection includes primary and secondary prevention of coronary heart disease, cardiosurgical procedures, and thrombolysis in acute myocardial infarction. Defining "cardioprotection" as "preservation of the heart" has also great theoretical implications, because all adaptive and compensatory mechanisms that directly or indirectly contribute to myocardial preservation have to be classified as "cardioprotective".
\end{abstract}

\section{Classification}

According to the definition given above cardioprotection can be classified as:

- Physiological adaptive and compensatory mechanisms

- Therapeutic approaches

A further distinction is that between acute and chronic mechanisms and interventions. The acute adaptive mechanisms serve mainly to provide an adequate myocardial energy supply, whereas the chronic mechanisms compensate for long lasting unfavourable influencesfor example, by structural remodelling.

Physiological adaptive and compensatory mechanisms

ACUTE MECHANISMS

It is not the aim of this article to provide a comprehensive list of all the numerous adaptive mechanisms operating in the heart. Some of the fundamental principles that underlie four main criteria will be discussed:

- Regulation of oxygen supply above the critical range

- Instantaneous adaptation of metabolic flow rates to current demands

- High reserve capacity of vitally important functions

- Multistage control of important protective and adaptive mechanisms

\section{Regulation of oxygen supply above the critical} range

The working heart depends exclusively on aerobic energy production. Myocardial oxygen reserve is very low-only $0.5 \mathrm{vol} \%$ is bound to myoglobin. Furthermore, even under resting conditions the heart extracts most of the oxygen provided by the coronary system, as indicated by a coronary venous $\mathrm{Po}_{2}$ of only $20 \mathrm{~mm}$ Hg. ${ }^{1}$ Because oxygen extraction cannot be substantially increased sufficient oxygen can be supplied under conditions of an increased myocardial workload only if coronary flow adapts instantaneously to the current demands. Under physiological conditions this adaptation occurs at a coronary venous $\mathrm{PO}_{2}$ of approximately $20 \mathrm{~mm} \mathrm{Hg} .{ }^{1}$ This value is much higher than the critical $\mathrm{PO}_{2}$ of less than $5 \mathrm{~mm}$ $\mathrm{Hg}$, at which mitochondrial respiration is limited. ${ }^{2}$ Not all the steps involved in the local metabolic regulation of coronary flow are fully understood, but this adaptive mechanism, which operates well above the critical $\mathrm{PO}_{2}$ and almost on a beat-to-beat basis, prevents myocardial damage with its deleterious consequences even if myocardial workload is increased dramatically.

\section{Instantaneous adaptation of metabolic flow rates} to current demands

Energy production under altered conditionssuch as ischaemia - should be adapted to as quickly as possible to avoid transient damage. If early in the ischaemic process the shift from aerobic to anaerobic glycolytic energy production was achieved only by activation of the initial step, by the end of the process increased lactate and ATP production could be achieved only by increasing activity at every step of the preceding reactions. Therefore, stimulation of flow exclusively at the entry reactions-the hexokinase and phosphorylase reactions- 
would substantially delay anaerobic energy production so that most anginal attacks would progress to necrosis and myocardial infarction.

An alternative to this entry controlled pathway is the multistage controlled pathway, at which all flow limiting and regulating steps are activated simultaneously. The principle of multistage control of the glycolytic pathway with simultaneous activation of all regulatory enzymes allows almost instantaneous adjustment of flow to current demands at all steps with an immediate increase in lactate and ATP production. ${ }^{4}$ When ischaemia is initiated, the breakdown of creatine phosphate is accompanied by an almost instantaneous increase in myocardial lactate production. This can only be achieved by multistage control of the glycolytic pathway. The mass action ratio of these regulating (allosteric) enzymes is far from equilibrium and shows further deviation under different experimental conditions. ${ }^{5}$

\section{High reserve capacity of vitally important} functions

Instantaneous adaptation of coronary flow to actual demands by local metabolic regulation can work only when oxygen supply by the coronary system exceeds energy demands even under extreme conditions of maximal workload. In experiments in dogs the metabolic reserve-determined as the oxygen supply during maximal coronary vasodilationexceeded, by about $100 \%$, the myocardial energy demands even during simultaneous maximal pharmacological stimulation of afterload, heart rate, and contractility. ${ }^{6}$ Similar conditions have to be assumed for humans. How else could Reinhold Messner have climbed (without oxygen supplementation), the Nanga Parbat and Everest where the partial oxygen pressure is only $40 \mathrm{~mm} \mathrm{Hg}$ ?

\section{Multistage control of important protective and} adaptive mechanisms

An essential principle is the protection of the heart against sympathetic over-stimulation and its deleterious consequences. This protection is based on several control steps:

- Autoinhibition of exocytotic noradrenaline release by activation of presynaptic $\alpha_{2}$ adrenoceptors via a negative feedback mechanism $^{7}$

- Similarly, adenosine formed in the myocardium inhibits exocytotic noradrenaline release by stimulating the presynaptic inhibitory adenosine A1-receptors ${ }^{8}$

- Reduction of $\beta_{1}$-adrenoceptors by internalisation, which uncouples the $\beta_{1}$-adrenoceptors from the stimulatory Gs-protein and from the effector enzyme adenylyl-cyclase. ${ }^{9}$

- Desensitisation of $\alpha_{1}$-adrenoceptor mediated responses ${ }^{10}$

- cAMP-dependent increase in the synthesis of inhibitory $\mathrm{G}_{\mathrm{i}}$ proteins $\mathrm{s}^{1112}$

- Short periods of myocardial ischaemia $(<10 \mathrm{~min}$ ) result in prolonged exposure of released noradrenaline to neuronal amine re-uptake (uptake ${ }_{1}$ ). Accordingly, rapid elimination of noradrenaline from the synaptic cleft via uptake ${ }_{1}$ becomes one of the major protective mechanisms in early myocardial ischaemia. ${ }^{13}$

After protracted periods of myocardial ischaemia ( $>10 \mathrm{~min}$ ) none of these protective mechanisms are operative and pronounced sympathetic overstimulation results. ${ }^{14}$

In addition specific adaptive mechanisms protect against specially harmful conditions, such as ischaemia. One of these is ischaemic preconditioning in which ischaemic tolerance is increased after short periods of myocardial ischaemia and reperfusion. ${ }^{15}$ Ischaemic preconditioning reduced infarct size and ventricular tachyarrhythmias and preserved myocardial function. ${ }^{16}$

\section{CHRONIC MECHANISMS}

Chronic mechanisms compensate for long acting potentially harmful conditions, such as increased workload or ischaemia. These chronic compensatory mechanisms, however, can have unfavourable side effects. Chronic compensatory mechanisms include activation of neurohormonal systems, morphological and functional changes (such as ventricular hypertrophy and ventricular dilatation), and metabolic changes-for example, in hibernating myocardium.

\section{Neurohormonal activation}

In patients with moderately impaired left ventricular function increased sympathetic activity may be beneficial because, it allows adaptation of heart rate and contractility. With progression of the cardiac disease, however, sympathetic stimulation becomes detrimental by increasing peripheral resistance and electrical instability, and thus increases mortality. ${ }^{17}$ In patients with severe congestive heart failure the plasma noradrenaline concentration is a very sensitive indicator of an unfavourable prognosis: it is more sensitive than the ejection fraction, for example. ${ }^{18}$ Similarly, stimulation of the renin-angiotensin-system in congestive heart failure may initially have beneficial effects but as the disease progresses, its effects become detrimental.

\section{Left ventricular hypertrophy and left ventricular dilatation}

Left ventricular hypertrophy is, independently of the underlying cause, a risk factor for lifethreatening ventricular tachyarrhythmias, as shown in the Framingham study. ${ }^{19}$ Left ventricular dilatation with enlarged end systolic and end diastolic volumes is accompanied by an almost exponential rise in mortality. ${ }^{20}$

Both ventricular hypertrophy and dilatation operate in remodelling after myocardial infarction: hypertrophy in the non-infarcted area and dilatation in the infarcted area. ${ }^{21}$

\section{Hibernating myocardium}

Hibernation is a mechanism to protect against chronic myocardial ischaemia. It is a reversible state of impaired myocardial function at rest that reduces metabolic demands. ${ }^{22}$ Although hibernation may reduce and/or delay cellular injury and myocardial necrosis in the ischaemic region of the heart, the loss of con- 
tractile myocytes in the hibernating myocardium increases the load on the residual normal myocardium.

In contrast to the acute adaptive mechanisms, the chronic compensatory mechanisms, therefore, evoke not only beneficial cardioprotective effects but also unwanted side effects. The ratio of favourable cardioprotective effects to deleterious side effects depends on the activation of the compensatory mechanism. Generally, the more a compensatory mechanism is activated the more severe are its deleterious consequences.

\section{Therapeutic approaches}

Like the physiological adaptive and compensatory mechanisms, treatments too can be acute or chronic.

\section{ACUTE INTERVENTIONS}

The major aim of acute interventions is to prevent the loss of functional myocardium and thus preserve ventricular function. Acute interventions include the restoration of coronary perfusion by thrombolysis and/or percutaneous transluminal angioplasty in acute myocardial infarction or prosthetic valve replacement in severe aortic stenosis. Detrimental effects result only from unwanted side effects or complications but not from the treatment itself.

Artificial cardiac arrest during cardiac surgery is a special form of cardioprotection. Experimental and clinical data have established that cardioplegia has cardioprotective effects. These include limitation of myocardial damage, which reduces postoperative mortality and complications and improves long term prognosis. ${ }^{23}$

\section{CHRONIC INTERVENTIONS}

Chronic interventions include long term pharmacotherapy, mainly in patients with congestive heart failure and/or coronary heart disease.

\section{Congestive heart failure}

In patients with impaired left ventricular function ACE inhibitors have been shown not only to reduce mortality but also to prevent the transition to severe congestive heart failure. ${ }^{17}$ According to the results of Veterans Heart Failure Trial (V-HeFT) I pure peripheral vasodilatation produced by the combination of hydralazine and isosorbide dinitrate significantly reduced mortality. ${ }^{24}$ This positive effect, however, was more pronounced when ACE inhibitors were used, as shown in V-HeFT II. ${ }^{25}$ The beneficial effect of ACE inhibitors has, therefore, to be based on additional mechanisms as well as afterload reduction by pure peripheral vasodilatation. Pure vasodilators, such as hydralazine, increase sympathetic activity: ACE inhibitors, however, do not have this unwanted side effect. ${ }^{26}$

The results of trials with vasodilating $\beta$ adrenoceptor blockers reinforce the importance of sympathetic stimulation in congestive heart failure. In a recent prospective randomised multicentre trial carvedilol, a $\beta$ adrenoceptor blocker with $\alpha$ adrenoceptor blocking properties reduced mortality in heart failure patients who were already being treated with an ACE inhibitor by $67 \%$. The Data and Safety Monitoring Board recommended premature termination of this study. ${ }^{27}$

\section{Coronary heart disease}

The treatment of patients with coronary heart disease can be evaluated by:

- Improvement of symptoms-that is, relief of angina

- Reduction of myocardial ischaemia, mainly based on the reduction of ST segment depression during stress electrocardiography

- Improvement in prognosis-that is, a reduction in mortality.

Three major classes of anti-ischaemic drugs are currently used in patients with coronary heart disease-these are nitrates, calcium channel blockers, and $\beta$ adrenoceptor blockers. Their efficacy in ameliorating symptoms and reducing the incidence of myocardial ischaemia is well established. However, they have different effects on outcome. These have been reviewed elsewhere. ${ }^{28}$

There are few studies of nitrates and these were of small numbers of patients. Furthermore, some of the studies were evaluated retrospectively. In essence, the data obtained with nitrates do not convincingly demonstrate improvement in prognosis.

In theory calcium channel blockers should have cardioprotective effects. In patients with unstable angina and with acute myocardial infarction, however, all studies were negative; as were studies of nifedipine, diltiazem, and verapamil. Studies of secondary prevention during the post-infarction period were also negative, except for three studies of a subgroup of patients without signs of heart failure. ${ }^{28}$

$\beta$ Adrenoceptors, unlike nitrates and calcium channel blockers, do improve prognosis. Due to the small number of patients this is only true with some limitations for patients with stable angina. An improvement in prognosis, however, was convincingly demonstrated in patients with unstable angina (as shown by HINT (Holland Interuniversity Nifedipine/Metaprolol Trial) and the study by Yusuf $e t a l$ ), in patients with acute myocardial infarction (as shown by the International Study of Infarct Survival 1 study), and in the postinfarction period (as shown by the Norwegian Multicenter study and the Betablocker Heart Attack trial). ${ }^{28}$ There was no improvement in prognosis, however, when $\beta$ adrenoceptor blockers with intrinsic sympathetic activity were used-for example, in the European infarct study with oxprenolol. ${ }^{28}$

The different effects of $\beta$ adrenoceptor blockers and calcium antagonists on outcome cannot be explained by their haemodynamic profiles. Both $\beta$ adrenoceptor blocking agents and calcium channel blockers reduce coronary perfusion pressure: in addition $\beta$ blockers increase peripheral resistance-which is an unwanted effect. 
The lack of an effect on outcome of calcium channel blockers-especially those of the nifedipine type-is probably related to their reflex activation of sympathetic activity, as shown by the increase in plasma catecholamines and heart rate. ${ }^{28}$

The idea that the cardioprotective effects of $\beta$ adrenoceptor blockers are directly related to their antiadrenergic properties is supported by two clinical findings:

- Improvement of prognosis applies only to $\beta$ adrenoceptor blockers without intrinsic sympathetic activity.

- During the post-infarction period the cardioprotective effect of $\beta$ adrenoceptor blocking agents - that is, reduction of reinfarction-is directly related to their reduction in heart rate-that is, their antiadrenergic efficacy. ${ }^{29}$

Chronic cardioprotective interventions by pharmacotherapy in patients with congestive heart failure and coronary heart disease cannot be exclusively explained by haemodynamic effects. Outcome is improved by other pharmacological effects, such as inhibition of the sympatho-adrenergic system and of the reninangiontensin-system.

1 Feigl EO. Coronary physiology. Physiol Rev 1983;63: $1-205$.

2 Fabel H, Lübbers DW, Rybak R. Die Bestimmung des Myoglobingehaltes und des kritischen Sauerstoffdruckes am schlagenden Kaninchenherzen "in situ" [abstract]. Pflüger's Arch Physiol 1964;279:R32.

3 Kübler W. Tierexperimentelle Untersuchungen zum Myokardstoffwechsel im Angina-Pectoris-Anfall und beim Herzinfarkt. Bibliotheca Cardiologica No. 22. Basel, New York: S Karger, 1969:1-93.

4 Kübler W, Spieckermann PG. Changes in glycolysis and high energy phosphates during myocardial ischemia with intermittent coronary perfusion. Cardiology 1971;56: intermis.

5 Kübler W, Spieckermann PG. Regulation of glycolysis in the ischemic and the anoxic myocardium. $\mathcal{F}$ Mol Cell the ischemic and the
Cardiol 1970;1:351-77.

6 Tauchert M. Koronarreserve und maximaler Sauerstoffverbrauch des menschlichen Herzens. Basic Res Cardiol 1973;68:183-223.

7 Starke K. Presynaptic receptors. Annu Rev Pharmacol Toxicol 1981;21:7-30.

8 Richardt G, Waas W, Kranzhöfer R, Mayer E, Schömig A. Adenosine inhibits exocytotic release of endogenous noradrenaline in rat heart: a protective mechanism in early myocardial ischemia. Circ Res 1987;61:117-23.

9 Harden TK. Agonist-induced desensitization of the beta- adrenergic receptor-linked adenylate cyclase. Pharmacol Rev 1983;35:5-32.

10 Bristow MR. Changes in myocardial and vascular receptors in heart failure. $\mathcal{F}$ Am Coll Cardiol 1993;22(suppl A): in heart faily.

11 Feldman AM, Cates AE, Veazey WB, Hershberger RE, Bristow MR, Baughman KL, et al. Increase of the 40000 -mol wt pertussis toxin substrate (G protein) in 40000 -mol wt pertussis toxin substrate (G protein) in

12 Neumann J, Schmitz W, Scholz H, von Meyerinck L Döring V, Klamar P. Increase of myocardial Gi-proteins in human heart failure. Lancet 1988;ii:936-7.

13 Dart AM, Schömig A, Dietz R, Mayer E, Kübler W. art AM, Schömig A, Dietz R, Mayer E, Kübler W.
Release of endogenous catecholamines in the ischaemic myocardium of the rat. Part B: effect of sympathetic nerve stimulation. Circ Res 1984;55:702-6.

14 Kübler W, Strasser RH. Signal transduction in myocardial ischemia. Eur Heart f 1994;15:437-45.

15 Lawson CS, Downey JM. Preconditioning: state of the art myocardial protection. Cardiovasc Res 1993;27:542-50.

16 Murry CE, Jennings RB, Reimer KA. Preconditioning with ischemia: a delay of lethal cell injury in ischemic myocardium. Circulation 1986;74:1124-36.

17 Rector TS, Cohn JN. Prognosis in congestive heart failure. Annu Rev Med 1994;45:341-50.

18 Cohn JN, Levine TB, Olivari MT, Garberg V, Lura D, Francis GS, et al. Plasma norepinephrine as a guide to prognosis in patients with chronic congestive heart failure. $N$ Engl F Med 1984;311:819-23.

19 Levy D, Anderson KM, Savage DD, Balkus SA, Kannel WB, Castelli WP. Risk of ventricular arrhythmias in left ventricular hypertrophy: the Framingham heart study. ventricular hypertrophy: the

20 Hammermeister KE, DeRouen TA, Dodge HT. Variables predictive of survival in patients with coronary disease: predictive of survival in patients with coronary disease: selection by univariate and multivariate analyses from
clinical, electrocardiographic, exercise, arteriographic, clinical, electrocardiographic, exercise, arteriographic, and quantitative

21 Pfeffer MA, Braunwald E. Ventricular remodeling after myocardial infarction. Circulation 1990;81:1161-72.

22 Rahimtoola SH. The hibernating myocardium. Am Heart $\mathcal{f}$ 1989;117:211-21.

23 Bretschneider HJ, Gebhard MM, Gersing E, Preusse CJ, Schnabel PhA. Recent advances for myocardial protection. In: Kaplitt MJ, Borman JB, eds. Concepts and controversies in cardiovascular surgery. Norwalk, CT: Appleton-Century-Crofts, 1983:174-85.

24 Cohn JN, Archibald DG, Phil M, Ziesche S, Franciosa JA, Harston WE, et al. Effect of vasodilator therapy on mortality in chronic congestive heart failure-results of a Veterans Administration Cooperative Study. $N$ Engl $\mathscr{f}$ Med 1986;314:1547-52.

25 Cohn J, Johnson G, Ziesche S, Cobb F, Francis G, Tristani $\mathrm{F}$, et al. A comparison of enalapril with hydralazineisosorbide dinitrate in the treatment of chronic congestive heart failure. N Engl f Med 1991;325:303-10.

26 Story DF, Ziogas J. Interaction of angiotensin with noradrenergic neuroeffector transmission. Trends Pharmacol drenergic neuroeffectc

27 Packer M, Bristow MR, Cohn EN, Colucci WS, Fowler MB, Gilbert EM. Effect of carvedilol on the survival of patients with chronic heart failure (abstract). Circulation patients with chronic
1995;92 suppl:I-142.

28 Rauch B, Kübler W. Antianginal medication. Current Opinion in Cardiology 1991;6:511-23.

29 Kjekshus JK. Importance of heart rate in determining beta-blocker efficacy in acute and long-term acute myocardial infarction intervention trials. $\mathrm{Am} \mathcal{F}$ Cardiol 1986;57:43F-9F. 